\title{
Lemmikloomapidamine: õigustused ja vastuväited
}

Juhan Javoiš

\begin{abstract}
Teesid
Lemmikloomana defineerin inimese psüühiliste vajaduste rahuldamise otstarbel inimese juures peetavat looma. Lemmikloomapidamine on muutunud massiliseks alles viimasel ajal ja vajab seega analüüsi. Käsitlen lemmikloomapidamise fenomeni nii inimese kui ka looma seisukohalt. Inimene rahuldab lemmikloomapidamisega erinevaid vajadusi: rudimentne loomapidamisvajadus, loodusläheduse vajadus, vanemlik instinkt, allutamiskirg, seiklusjanu, sotsiaalsed vajadused. Looma heaolu kriteeriumiks pean tema geneetiliste eelduste rakendatust elukeskkonnas. Tavaliselt surub inimkaugete (vs. sünantroopsete) loomade pidamine lemmikloomadena nende heaolu alla, nende vajadustest täidetakse vaid primaarsemad. Seda ei pruugi loomapidaja aga märgata inimese ja looma suhtlusbarjääri tõttu, samuti põhjusel, et loom üritab "halva mängu juurde head nägu teha", st jääb optimistiks. Kui inimkauge looma pidamine pole välditav, on soovitav valida intelligentsemad, st kohanemisvõimelisemad liigid. Inimkaugetele liikidele tuleks eelistada sünantroopseid loomi, kelle heaolu lemmikloomana võib olla maksimaalne.
\end{abstract}

Märksõnad: inimese ja looma suhtlusbarjäär, lemmikloom, lemmikloomapidamine, looduslik loom, looma heaolu, loomapidamiseetika, loomapsühholoogia

Olen ise palju erinevaid lemmikloomi pidanud. Peamiselt just metsikuid, st vabast loodusest püütud loomi. Seetõttu arvan end olevat adekvaatne loomapidamise õigustuse teemal sõna võtma, seda enam, et tõsiseid lemmikloomateadlasi on vähe. Juba sõna "lemmikloom" defineerimine on raske. Käesolevas kirjutises defineerin lemmikloomana inimese psüühiliste vajaduste rahuldamise otstarbel inimese juures peetava looma.

Selles mõttes vastandan lemmiklooma teistele koduloomadele, kes rahuldavad otsesemaid vajadusi, nagu toit, materjalid, teenindus (jaht, valvamine, hiirte püüdmine) jms. Nõnda defineerituna võib öelda, et lemmikloomade pidamine on muutunud massiliseks

http://haldjas.folklore.ee/tagused/nr31/javois.pdf 
alles üsna viimasel ajal. Näiteks Suurbritannias on tänaseks lemmikloomi juba rohkem kui pooltes peredes (Alderton 2000). Et ka looduskaitselised ja eetilised küsimused hakkavad viimasel ajal üha enam tähtsustuma, vajab lemmikloomapidamine kui nähtus selgeksmõtlemist ja -rääkimist. Kas ja kust jookseb siin loomaarmastuse ja loomapiinamise piir?

Järgnevas kirjutises vaatlen esmalt lemmikloomade pidamist inimlikust vaatenurgast, seejärel üritan seda teha looma seisukohalt, vaen looma ja inimese vahelise arusaamatuse põhjusi ja annan lõpuks paar asjakohast soovitust.

\section{Miks peab inimene lemmikloomi?}

Hamlyni lemmikloomade hooldamise entsüklopeedia (Alderton 2000) väidab olevat "väljaspool kahtlust", et inimesed, kes peavad lemmikloomi, on keskmisest tervemad, taastuvad kiiremini haigustest ja nende eluiga on keskmisest pikem. Lemmikloomi kasutatakse pikaajaliste voodihaiguste, autismi, Alzheimeri tõve, õpiraskuste jpm raviks või leevendamiseks. Lapsed, kes kasvavad koos lemmikloomadega, olla enesekindlamad, vähem enesekesksed ja aktiivsemad. Muu hulgas on mainitud, et lemmikloomad aitavad koolis huvitavaks teha muidu "surmigavad" õppeained, näiteks bioloogia.

Tõepoolest on ilmne, et teatud tüüpi inimesed, eelkõige lapsed, tunnevad lausa vastupandamatut rõõmu lähedusest mõne loomaga ja instinktiivset vajadust neid kinni püüda ja sundida endaga koos elama. Tuntuim näide on muidugi maailmakuulus loomaaednik Gerald Durrell, kes selliseid kihkusid ka värvikalt oma raamatutes kirjeldab (vt nt Durrell 1994). Täiskasvanuks saades leidis ta oma tegevusele ka ettekäände: ohustatud liikide kaitse. On aga selge, et tegu on ettekäändega, sest ta alustas selle harrastusega ammu enne, kui tal looduskaitsest aimugi oli. Teise äärmusliku näitena meenub telesaates "Pealtnägija" (Eesti Televisioon, 13. oktoober 2004) nähtud tädike, keda tutvustati Švejki äriidee maaletoojana: vanaproua maja sõna otsese mõttes kubises kõikmõeldavaist elukaist, kes lausa tallasid üksteise turjal. Ise ta aga kurtis, et ilma nendeta küll elada ei suudaks.

Võtab tõsiselt mõtlema, kust küll pärineb lemmikloomade pidamise vajadus. Olles tegelnud oma õpingute käigus evolutsiooniteoo- 
riaga tõsiselt, olen veendunud, et peame seletust otsima inimese evolutsioonilisest ajaloost, loodusliku valiku käigus välja kujunenud instinktidest ehk tungidest. Realistlikke hüpoteese tuleb pähe mitu. Üsna ilmselt domineerivad erinevate loomaliikide ja erinevate inimeste puhul täiesti erinevad põhjused. Eristaksin neist: rudimentne loomapidamisvajadus, vanemlik hoolitsemisinstinkt, vajadus looduse läheduse järele, allutamistung, seiklusjanu, sotsiaalsed vajadused.

\section{Rudimentne loomapidamisvajadus}

Ilmsesti on enamik ühiskondi olnud ajalooliselt rohkem või vähem karjakasvatajad. Hea läbisaamine loomadega, nauding loomadega tegelemisest on otseselt määranud inimese edukuse neis ühiskondades. Sedakaudu on looduslik valik kujundanud inimesest loomapidaja. Tänapäeval pole enamikul inimestel vajadust ega võimalust koduloomi pidada, aga tung on säilinud ja seda kompenseeritakse lemmikloomade hooldamisega. Üsna sageli kuuleme tänapäeval ka traditsiooniliste koduloomade omanikelt, näiteks veisepidajailt, et loom tegelikult mingit tulu ei too või toodab koguni lausa kahjumit. Tšõngõz Ajtmatov (1983) kirjeldab, kuidas nõukogude võim sundis traditsioonilisi karjakasvatajaid kortermajadesse elama. Psüühilise tasakaalu säilitamiseks üritasid nad korteris kitsi ja lambaid pidada - ja kui see ei õnnestunud, leidsid väljapääsu enesetapus. Kõneldes aga paadunud linnainimestest - kes meist pole tundnud naudingut näiteks akvaariumi puhastamisest või uuest avaramast hamstripuurist -, siis tõenäoliselt kihutab neid takka eeskätt ürgne karjapidaja.

\section{Vanemlik instinkt}

Esimesena on ehk Konrad Lorenz (vt Mänd 2004) tabavalt välja toonud, et kõik, mis inimesega sarnaneb, aga on inimesest pisem ja ümaram, meenutab talle tema lapsi ja tekitab hoolitsemisvajadust. Kui sellise instinkti tõttu hoitakse enda juures vabast loodusest püütud loomi, sarnaneb tulemus n-ö Münchauseni sündroomiga (Thomas 2003) - ohtliku käitumishäirega, mille puhul vanemad tekitavad lapsele kannatusi, võimaldamaks endale nende eest rohkem hoolitseda. Sellise juhtumi põhjalik kirjeldus leidub Eno Raua lasteraamatus Jälle need naksitrallid (Raud 1986). 
Miks inimesed eelistavad lemmikloomi sageli ka siis, kui neil on võimalus kulutada energiat oma tõelistele järglastele? Üheks võimalikuks põhjuseks on minu arvates asjaolu, et lemmikloomade pidamine on laste kasvatamisest mitmeti mugavam: loom on tavaliselt lihtsama ja ettearvatavama käitumisega kui laps, võib alluda tunduvalt kergemini kontrollile ja - last but not least - loom on piisavalt võõras olend, et põhjustada vähem muret või südamevalu kui laps.

\title{
Loodusläheduse vajadus
}

Inimeste elukeskkond ja eluviis on just viimastel aastakümnetel väga kiiresti muutunud. Kõik meie ümber on muutunud tehislikuks ehk antropogeenseks, alustades linnapildist ja lõpetades teleseriaalidega.

Inimene pole jõudnud puhttehisliku keskkonnaga veel kohastuda. Seetõttu tunneb ta end ebamugavalt ja vajab toetuspunktideks märke endisest keskkonnast, mitteantropogeenset informatsiooni. Seda võivad pakkuda naturaalsed sisustusmaterjalid, toataimed, loodusekskursioonid, aga muidugi ka lemmikloomad. Sellised toetuspunktid aitavad mitme psüühikahäda vastu, näiteks autistlikud lapsed suhtlevad tihti parema meelega lemmikloomade kui pereliikmetega (Alderton 2000). Pangem tähele, et lemmikloomade pidamine on eelkõige levinud just linnaelanike seas, maaelanikes võib see mõnikord lausa võõristust tekitada või neile nalja valmistada.

\begin{abstract}
Allutamiskirg
Ajaloo vältel on inimese evolutsioon kulgenud suunas "me ei tohi oodata looduselt armuande, vaid peame neid temalt võtma”. Eelkõige meeste edu järglaste soetamisel on ajalooliselt sõltunud sellest, kui paljut suudavad nad enda ümber allutada, alustades liigikaaslastest ja lõpetades kas või puude langetamisega majaehituseks.

Inimese allutajalikust loomusest tuleks otsida põhjust, miks soovitakse võimalikult eksootilisi ja kummalisi lemmikloomi, selle asemel et rahulduda näiteks lihtsa kodukassiga. See on ilmselt ka põhjus, miks valitakse võimalikult suurt ja kurja tõugu koeri, miks muistsed ülikud pidasid puurides kiskjaid või miks rõngast läbi hüppav lõvi erutab meid palju enam kui näiteks rõngast läbi hüppav lammas.
\end{abstract}




\section{Seiklusjanu}

Eelkirjeldatud vajadusega on tihedalt seotud seiklusjanu. Paljud loomad on loodusliku valiku käigus muutunud inimesele eemaletõukavaks - tegu võib olla mürgiste (lülijalgsed, roomajad) või ajalooliselt ohtlikke haigusi kandvate (närilised) liikidega.

Lähedusest sellise loomaga võib kujuneda inimesele "seiklushormooni" adrenaliini ja seega lõbutunde allikas, sarnaselt näiteks õudusfilmide või benji-hüpetega. Eelkõige seiklusjanuga näib seletuvat mürgiste loomade, nagu skorpionid, ämblikud, piraajad, maod, valimine lemmikloomaks, aga mingil määral kindlasti ka hiirte, rottide, prussakate ja sisalike pidamine.

\section{Sotsiaalsed vajadused}

Inimene on äärmiselt sotsiaalne loom, ta vajab oma käitumisele tagasisidet ning kaaslaste tunnustust ja eeskuju. Suhtluspartnerina võib loom olla palju usaldusväärsem kui inimene - näiteks koera tunded on lihtsad ja läbinähtavad ning et ta üldse eriti ei mõtle, võib olla kindel, et ta ei mõtle halvasti. Ta käitub oluliselt loomulikumalt ja sundimatumalt enamikust tänapäeva inimestest - ja annab meile sellega tihti väga vajalikku eeskuju.

Lemmikloom võib olla ka väljund kaasinimestega suhtlemiseks. Näiteks ühes uuringus leiti, et koeraomanikest lapsi hakkasid eakaaslased sagedamini külastama (Paul \& Serpell 1996).

Hinnaline või haruldane lemmikloomatõug võib olla ka staatusesümboliks.

\section{Mida loomad tunnevad?}

Inimene rahuldab lemmikloomi pidades oma vajadusi ja suurendab nende abil oma heaolu. Intuitiivselt arvab ta, et tema suhetes loomadega on kõik korras, kui ta ennast ise hästi tunneb. Kui inimene tüdineb akvaariumikaladest, laseb ta need tualetipotist alla, kui koerast, viib looma varjupaika, kui kass kuseb tuppa, laseb inimene ta kastreerida, papagoid aga peab puuris, sest nii on lihtsam tema tagant koristada. Selline silmaklappidega puhtegoistlik lähenemine on eluslooduses loomulik. Kas aga tegelikult lemmikloomade heaolu suureneb või väheneb kooselust inimesega? Kust lä- 
heb piir loomaarmastuse ja loomapiinamise vahel? Sellele küsimusele vastamiseks ei piisa "kõhutundest".

Kui järele mõelda, on looma heaolu kriteeriume väga raske määratleda. Võime teha katseid, selgitamaks, milliseid tingimusi loom mingis olukorras eelistab. Aga alati sellest ei piisa - ei tohi unustada, et looma eelistused on kujunenud väga pika aja vältel, toimimaks üksnes ajaloolises keskkonnas, ja võivad vaese eluka võõras olukorras (mida inimese seltskond enamasti pakub) viia ummikusse (näiteid toon allpool). Nii ebaaus kui see demokraatlikus ühiskonnas kasvanud inimesele ka ei tundu, ei saa ta looma heaolu määratledes lähtuda üksnes looma enda hetketahtest.

Lähenegem evolutsiooniteooria vaatenurgast: iga elusolendi iga tegevuse ultimatiivne eesmärk on anda võimalikult palju ja võimalikult häid järglasi. Kas järglaste arv kõlbab heaolu kriteeriumiks? Mõtleme. Väidetavalt piisaks mehe ühe ejakulatsiooni käigus väljastatavatest seemnerakkudest, et viljastada kõik Ameerika Ühendriikide naised. Kui see mõne mehega tõesti teostuks ja seejärel sunnitaks teda kogu ülejäänud aja mungaelu elama, kas tema heaolutunne sellest kasvaks? Vaevalt. Ehkki ultimatiivselt on kõik inimese (resp. looma) tegevused suunatud järglaste arvu suurendamisele, ei tähenda see, et nendest tegevustest saadav rahuldus oleks tema heaolutundele vähem tähtis kui lõppeesmärk ise.

Selleks, et saavutada lõppeesmärki, on meil läbi aegade olnud tarvilik tunda naudingut ka kõigist selleni viivatest toimingutest. Ja tunda ebamugavust (ärevust, valu, hirmu), kui nende toimingute teostamist ei võimaldata. Sellisest arutlusest lähtudes määratleksin, et looma heaolu taset näitab see, kuivõrd kõik tema geneetilised eeldused leiavad rakendust tema elukeskkonnas.

Konkreetsest määratlusest võib juba järeldada, millistel tingimustel tunnevad lemmikloomad end paremini ja millistel halvemini. Esimene järeldus on selgelt: mida pikem on vaadeldava loomaliigi või -sordi evolutsiooniline ajalugu inimese seltskonnas, seda paremini on ta selleks kohastunud, seda kõrgem saab olla tema heaolu lemmikloomana.

Bioloogia arenedes saab üha selgemaks, kuivõrd täpselt on organismid oma keskkonnale kohastunud. Pika ajalooga koduloomad - nt koer, kass, veis - võivad end inimese juures tunda hästi, paremini kui kus tahes mujal. Lühikese ajalooga koduloomad - nt rott, kuldkala, küülik - tunnetavad tõenäoliselt konflikti oma ürgsema- 
te geenide ja inimkeskkonna vahel. Paljud sünantroopsed ehk inimkaaslejad loomad - tuvi, kärbes, prussakas - võivad oskusliku pidamise korral tunda end sama mõnusalt nii siin- kui ka sealpool terraariumiseina. Kuid otse metsikust loodusest pärinevate (tähistagem neid edaspidi lühiduse huvides sõnaga looduslikud) loomaliikide pidamine lemmikloomadena surub nende heaolu räigelt alla nende geneetilised eeldused on suunatud hoopis teistsugusele keskkonnale.

Dokumentaalfilmis The Beast Within (Grainger 2003) küsitakse lõvitaltsutajalt, kas tema arvates on lõvid oma eluga vangistuses rahul. "Nad ei tea looduslikust keskkonnast mitte midagi. Nad on vangistuses sündinud. Nad ei oskagi mujale tahta!" vastab taltsutaja tähtsa eksperdihäälega.

Ülaltoodud loogikaga on äratuntavalt varustatud teisedki sellised juhud, kui isegi (või eelkõige?) loomadega lähedalt tegelevad inimesed kasutavad kodukootud antropotsentristlikke mõttearendusi. Lõvi poleks lõvi, kui ta tunneks end puuris sama mõnusalt kui savannis. Kurb on jalutada loomaaias, kus täpselt sama kujundusega aedikutes vaevlevad totaalselt erinevad sõralised ja kiskjad, standardsetes terraariumides molutavad kõige fantastilisemad roomajad jne. Iga loomaliiki eristavad teistest miljonid omadused, alustades raku biokeemiast ja lõpetades lihaste paigutuse ning naha paksuse ja omadustega. Samamoodi on igal neist loomaliikidest miljoneid just neile vajalikke keskkonnategureid, mille puudumine paneb neid end halvasti tundma.

Loomade heaolu näitlikustamiseks võib vabalt rakendada üldtuntud Maslow' vajaduste püramiidi (Huitt 2004). Kui pidada looduslikku looma lemmikloomana, saab tema vajadustest reeglina rahuldada vaid esmaseid - kindlustada toidu ja joogi, ehkki ka need ei vasta kaugeltki ideaalsele, st looduslikule söögisedelile.

Turvalisuse vajadusega on lood juba väga kehvasti, eriti kui loom on kohastunud kõrge kisklusriskiga, st on loomupäraselt äärmiselt arglik, nagu näiteks mitmed närilised.

Looma sotsiaalseid vajadusi ja vajadust sigida on väga raske rahuldavalt täita, sest enamasti ei võimaldata lemmikloomadel ise oma asustustihedust määrata. Paljud liigid ei sigi vangistuses üldse. (Aga kujutage ette, kui halb peab olema, kui isegi sigida ei taha!) Neil, kes sigivadki, on looma enda roll paaritamises enamasti palju väiksem ja ebaloomulikum, kui see oleks looduses. Isegi paljud pika traditsiooniga sünantroopsed lemmikloomad kastreeritakse, harul- 
dast liiki lemmikloomadel puudub aga tihti võimalus elu jooksul ainsagi liigikaaslasega kohtuda.

Eneseteostusvajaduse võiks loomade puhul ümber sõnastada: vajadus, et keskkond esitaks võimalikult palju just neid väljakutseid, mille täitmiseks loom on kohastunud. Selle vajaduse täitmisega on lood enamasti lootusetud.

Kui püüda keskmise loodusliku looma enesetunnet ette kujuta$\mathrm{da}$, siis elu inimese juures tundub neile tõenäoliselt mingi painava narkounenäona, kus kõik asjad on kuidagi veidrad ja valesti. Loodusesõbrad loevad naudinguga kuulsa käitumisteadlase Konrad Lorenzi kirjeldust sellest, kuidas ta asendas metshanedele ema (Lorenz 1984). Tegelikult pole siin nunnut ja toredat rohkem kui juhtumites, kus metsloomad on üles kasvatanud inimlapsi. Kummalgi juhul ei tunne lapsed end ilmselt kaugeltki nii hästi kui oma tõelise ema seltsis.

Muidugi, ka looduslik keskkond on muutlik, järelikult peavad loomad olema kohastunud võoras olukorras hakkama saamiseks. Ent nii järske muutusi, nagu toob vägivaldne kolimine inimese juurde, loodusliku looma elupaigas üldjuhul ette ei tule.

Siit edasi mõeldes võimegi tuletada teise reegli looduslike loomade heaolu hindamiseks lemmikloomana: mida intelligentsem, st õppimisvõimelisem loomaliik, seda paremini saab ta end tunda võorras keskkonnas.

Loomade intelligentsus ehk õppimisvõime pärineb nende ajaloolisest keskkonnast. Mida ebastabiilsem, muutlikum, ennustamatum on keskkond, seda paremini on liigil välja arenenud õppimisvõime, jäämaks muutunud keskkonnas edukaks (Bernays \& Chapman 1994). Peale inimese enda on kõige õppimisvõimelisemad teistest tunduvalt sotsiaalsemad loomad (kaaslaste käitumine on üsnagi raskesti ennustatav, võrreldes näiteks sobiva söömapaiga asukohaga) ja paljud sünantroopsed ehk inimkaaslejad loomad (põhjusel, et inimene ise elutseb kõige erinevamates kohtades). Ahvid, papagoid, rotid, hiired, kärbsed, prussakad - selliseid loomi iseloomustab plastilisus, nad võivad end hästi tunda väga erinevates elupaikades. Näitena "ideaalsest" lemmikloomast meenub Postimehes kirjeldatud juhtum hakist, kes asus külastama Haljala Gümnaasiumi, oli äärmiselt taltsas, lasi end silitada ja segas koolitunde (PM Online 2004). Ei saa välistada, et tegu võis olla vabadusse pääsenud endise lemmikloomaga, ent teades hakki kui äärmiselt sot- 
siaalset ja sünantroopset liiki, ei pane ka metsiku haki selline käitumine eriti imestama.

Siiski tekitab ülaltoodud reegel inimeses intuitiivset vastumeelsust. Kas tõesti tunneb näiteks juhm vihmauss end vangistuses halvemini kui intelligentne ahv? Just väga intelligentsete loomade püüdmine lemmikloomaks kätkeb endas inimese tavaettekujutuse järgi eriti suurt traagikat. Selline ettekujutus on osaliselt illusoorne ja osaliselt on sel tõepõhi all.

Esmalt illusioonidest. Meis on sügavalt juurdunud arusaam, et intelligentsemad loomad on võimelised tundma suuremaid kannatusi. Sellisele arusaamale tuginevad ka näiteks laboriloomade kohtlemise seadused, mis sätestavad, et katsete tegemiseks (loe: piinamiseks) tuleks eelistada väiksemal määral "tundlikke" loomi - väidetavalt põhjustatakse nii vähem kannatusi. Sealjuures peetakse tundetumaks just inimesest fülogeneetiliselt kaugemaid loomi: piinamise eelistusjärjekord näeb välja enamvähem selline: selgrootud, külmaverelised, soojaverelised, imetajad, primaadid (Porter 1992). Kummatigi pole evolutsiooniteooria valguses vähimatki põhjust arvata, et inimesest kaugemad organismid piinamise (või ebaloomuliku eluviisi) korral vähem kannataksid. Küll aga on põhjust arvata (vt allpool), et inimesed märkavad selliste organismide kannatusi vähem, saavad neist vähem aru.

Ent teiseks tõepõhjast. Üldistasin eespool - mida intelligentsem, st õppimisvõimelisem loomaliik, seda paremini saab ta end tunda võõras keskkonnas. Lähedane interaktsioon inimesega võib võimaldada intelligentsele loomale mõnusamat äraolemist kui "rangelt kodeeritud" loomale. Ent seda vaid juhul, kui hooldaja võtab tema psüühiliste vajaduste, tema "otsiva vaimu" rahuldamist tõsiselt. See on aga just intelligentsemate ja sotsiaalsemate loomaliikide puhul palju raskem kui vähemintelligentsete puhul. Seetõttu tõesti, intelligentse looma enesetunne vangistuses on tihtipeale äärmiselt halb. Nagu kirjutas Konrad Lorenz:

[---] kõrgemalt arenenud ja erksama siseeluga loomi saab vaid siis tundma õppida, kui nad tohivad vabalt liikuda. Kuivõrd vaese ja arenematu siseeluga on sellised puuri ahistatud papagoid ja ahvid, niivõrd uskumatult elavaks, kentsakaks ja huvitavaks muutuvad needsamad loomad, kui neile anda piiramatu vabadus (Lorenz 1984). 


\section{Miks inimesed loomi ei mõista?}

Kummati ei tunne enamik looduslike loomade pidajaid, et nad midagi paha teeksid (muidu nad vaevalt seda ju teeksidki). Kui hankida lemmiku loomuliku eluviisi kohta piisavalt teadmisi ja neid tema pidamisel hoolikalt rakendada, võib üsna tihti tunduda, et loom on parima tervise juures, toimetab sangviiniliselt oma igapäevaseid toimetusi ning on rõõmus ja rahul. Minu arvates on see enamasti illusioon, millel on kaks põhjust: (a) inimese ja looma suhtlusbarjäär ja (b) looma omadus jääda optimistiks, teha "halva mängu juurde head nägu".

\section{Inimese ja looma suhtlusbarjäär}

Vaatame otsa mõnele kalale, näiteks latikale. Tema nägu tundub mõtlik, võib-olla kergelt melanhoolne. Sellise "meeleolu" säilitab ta ka surmaeelsetes visklustes pärast seda, kui õngitseja on ta kaldale heitnud, või isegi soomuste rookimise ja sisikonna eemaldamise ajal. Võib-olla mõistus ütleb meile tõesti, et tegelikult vaene elukas kannatab, ja kuidas veel. Ent kalale otsa vaadates tõrgub alateadvus tunnistamast, et asi saab olla kuigi hull. Oleme harjunud suhtlema peaasjalikult inimestega, veelgi enam, ka ajalooliselt on meile olnud oluline ära tunda peaasjalikult just kaasinimeste tundeid ja seisundeid. Kokkupuuted näiteks latikaga on aga läbi aegade piirdunud üksnes püüdmise ja söömisega, mis pole võimaldanud empaatiavõimel kala tunnete suhtes välja kujuneda (välja arvatud ehk kala tunded püüniste vastu). Seetõttu oleme võimelised loomadelt vastu võtma eelkõige üksnes selliseid seisundimärke nagu kaasinimestelt.

Aga enamik loomi ei teavita meid oma seisundist nii, nagu kaasinimesed seda teeksid, st nii, et see vallandaks meis loomupärase kaastunde. Mida evolutsiooniliselt kaugem on loom inimesest, seda vähem on loogiliselt põhjust arvata, et tema signaalid ja kehakeel sarnanevad meie omadega ja et me tajume tema enesetunnet. Lisaks pole vähemsotsiaalse eluviisiga loomad kohastunud isegi liigikaaslasi oma hädadest teavitama. Nõnda suudamegi üsna muretult jälgida, kuidas meie armas lemmikskorpion tõmbub päev-päevalt rohkem krimpsu, kuni on ühel hommikul vaikselt elust lahkunud.

Suhtlusbarjäärist tingitud illusiooni õnge ei lähe mitte üksnes naiivsed lemmikloomapidajad, vaid - nagu ülalpool mainitud - seda võtab tõe pähe ka katseloomateadus. Filosoofiliselt on see võrrel- 
dav taimetoitlaste arusaamaga, et kuna taim näitab vähem välja, kannatabki ta tapmise ja ärasöömise tõttu vähem kui loom.

\section{Loomad jäävad optimistiks}

Teine põhjus, miks võib ekslikult tunduda, et looduslikel loomadel on inimese juures hea, on loomade omadus "halva mängu juurde head nägu teha", teisisõnu - võtta ka ebameeldivast olukorrast parim. Ka inimeste vanglaargipäev näeb välja üsna sangviiniline, eriti näiteks võõrkeelsele inimesele - või ka koerale. Vangistatud loomal pole aga isegi võimalust esitada presidendile armuandmispalvet, ta pole kohastunud unistama, käed rüpes, millestki muust kui just sellest olukorrast, kus ta hetkel on. Ta ei tule selle pealegi, et üritada oma õnnetu konutamisega vangistajale mõista anda tolle teo ebaviisakusest, isegi kui too oleks võimeline teda mõistma. Temale oleks see lihtsalt ajaraiskamine. Seetõttu jääb ta tavaliselt viimase füsioloogilise võimaluseni optimistiks ning asub toimekalt (ja pealtnäha rõõmsameelselt) tegutsema oma enesetunde parandamiseks, kui see on vähegi võimalik. See optimism kandub üle ka hooldajatele - lausa uskumatu, kui muhedana tundub loomaaednike endi pajatustes selline halvas mõttes koonduslaager, nagu seda on loomaaed (nt Durrell 1989).

Arusaamatus on veelgi suurem. Nagu juba eelmise peatüki alguses märkisin, ei pruugi ka loomade eelistused viidata, mis on nende heaoluks parim. Ernest Seton-Thompson (1974) kirjeldab ühes kurvas jutustuses puurilindu, kellele pärast aastatepikkust vangistust pakutakse vabadust. Linnus küll vallanduvad impulsid vabadusse minekuks, kuid lõpuks eelistab ta siiski jääda puuri. Ehkki tegu on ilukirjandusega, on juhtum vägagi tõetruu. Võõras keskkonnas on looma "programm" sassi aetud, talle pakutakse võõraid valikuid. Puurilind tegi enda olukorra kohta võib-olla isegi hea otsuse - vabanemisega kaasnev kiire keskkonnamuutus oleks võinud väärastatud loomakesele mõjuda tõesti hukutavalt. Ent kas selline otsus näitab, et kõnealuse liigi heaolu on puuris suurem kui looduslikus elupaigas?

Igasugune käitumine seisneb lihtsalt reflekside kujunemises ja vallandumises vastavalt stiimulitele. Kui inimene toob looma loomulikest erinevate stiimulitega keskkonda, pole midagi imestada, et tolle käitumine võib olla veider ja viia vaatleja kergesti kahtlase väärtusega järeldustele. E. Seton-Thompsoni jutustuse tõsielulises 
analoogis kirjeldab Gerald Durrell (1989), kuidas ta kord Paraguays oli sunnitud oma kolm kuud vangistuses peetud loomakollektsiooni taas vabadusse laskma, sest ei pääsenud nendega üle piiri. Paljud neist loomadest tolknesid veel kaua ümber laagriplatsi, ootasid toitmist ja üritasid puuridesse tagasi pääseda. Et neid ei viidud isegi nende püüdmispaika (tuttavasse kodupaika) tagasi, oli selline tagajärg minu arvates ootuspärane. Millise järelduse tegi kogenud loomauurija G. Durrell seepeale? Tsiteerin:

Just seda laadi kogemused loomadega on muutnud mind sallimatuks zookriitikute arutute etteheidete suhtes. Nende arvates on ülekohtune võtta loomalt "vabadus" (Durrell 1989:27).

G. Durrell püüab selle juhtumi abil näidata, et loomadel võib loomaaias olla mõnusamgi kui looduslikus elupaigas. Minule aga kerkis silme ette hoopis tuntud kirjeldus Siberi põlisrahvastest või indiaanlastest, keda on õpetatud alkoholi tarbima ja kes seejärel viinapoe ümber tolknevad. Nad pole lihtsalt uudsete stiimulitega kohastunud ja käituvad seetõttu ebaadekvaatselt. Lõunamaades on laialt levinud lülijalgne nimega hämmaline. On teada, et kui sellele elukale anda terraariumis piiramatult toitu, sööb ta end lõhki ja jätkab ka seejärel söömist (Giljarov \& Krõžanovski \& Mamajev et al. 1984). Me ei saa sellisest käitumisest järeldada, et lõhkisöömine suurendab tema heaolu. Looduses takistab täis kõht teda uut saaki püüdmast ja enesehävitamine on välistatud.

\section{Kokkuvõtteks soovitusi}

Millised lihtsad järeldused võiks ülaltoodust teha?

- Ehkki see on üha populaarsemaks muutumas, ei tasu võtta lemmikloomaks looduslikku looma. Ta võib ka kogenud silmale näida puuris rahulolev, kuid arvan, et tegelikult on tal halb. Ka kõige kogenum bioloog jääb hätta loodusliku looma kõigi vajaduste täitmisel. Papagoi puuri pigistamise asemel pange siilile piima või tihasele pekki.

- Lemmikloomaks sobib mõni sünantroopne loom, eelistatult inimese ammune sümbiont, näiteks koer või kass, sest need on kõige paremini kohastunud eluks lemmikloomana. Ta rahuldab kui mit- 
te kõik, siis enamiku teie vajadustest ja annab teile lisaks teadmise, et te ei tee talle liiga.

- Kui vajate looduslike loomade kogemust, vaadelge neid nende kodupaigas. Eesti looduses ei liigu trendikaid eksootilisi elukaid, kuid leidub arvukalt mitmeid kohalikke (näiteks metsvint, rohukonn ja ristämblik), kes on vähemalt sama huvitava käitumisega ja kellega tutvumisest võib saada palju suurema naudingu kui toanurgas akvaariumis konutavast püütonist. Meenutagem, et ka jalutuskäik looduses aitab paljuski rahuldada samu vajadusi mida lemmikloomad.

\section{Kirjandus}

Ajtmatov, Tšõngõz 1983. Ja sajandist on pikem päev. Nüüdisromaan. Tallinn: Eesti Raamat.

Alderton, David 2000. Hamlyni lemmikloomade hooldamise entsüklopeedia: Praktiline käsiraamat lemmikloomade valimiseks ja hooldamiseks. Tallinn: Varrak.

Bernays, Elizabeth A. \& Chapman, Reginald Frederick 1994. Host-plant selection by phytophagous insects. Contemporary topics in entomology 2. New York: Chapman \& Hall.

Durrell, Gerald 1989. Loomaaed saarel. Tallinn: Valgus.

Durrell, Gerald 1994. Minu pere ja muud loomad. Tallinn: RKE.

Giljarov, Merkuri S. \& Krõžanovski, Oleg L. \& Mamajev, Boris M. et al. 1984. Selgrootud. Loomade elu 3. Tallinn: Valgus.

Grainger, Greg 2003. The Beast Within. Grainger Television Australia Pty. Ltd.

Huitt, William G. (Bill) 2004. Maslow's hierarchy of needs: Educational Psychology Interactive. Valdosta (GA): Valdosta State University (http:// chiron.valdosta.edu/whuitt/col/regsys/maslow.html - 15. detsember 2005).

Lorenz, Konrad 1984. Kuningas Saalomoni sõrmus: [Loodusehuvilistele loomade käitumisviisidest]. Tallinn: Valgus.

Mänd, Triinu 2004. Lemmikloom kui pesaparasiit. Interdistsiplinaarne seminar "Inimesed ja lemmikloomad" 26.-27. oktoobril 2004 Eesti Kirjandusmuuseumi saalis: Teesid. Tartu: Eesti Kirjandusmuuseumi Folkloristika Osakond \& Eesti Folkloori Instituut, lk 6-7 (http://www.folklore.ee/ pubte/loomad/tees.pdf - 15. detsember 2005). 
Paul, Elizabeth S. \& Serpell, James A. 1996. Obtaining a new pet dog: Effects on middle childhood children and their families. Applied Animal Behaviour Science 47, lk 17-29.

Pealtnägija. Eesti Televisioon, 13. oktoober 2004.

PM Online 2004. Noor hakk käib koolitundides. Postimees 19. oktoober (http://www.postimees.ee/191004/esileht/midagi_erilist/147728.php - 15. detember 2005).

Porter, David G. 1992. Ethical scores for animal-experiments. Nature 356 (6365), lk 101-102.

Raud, Eno 1986. Jälle need naksitrallid I-II. Tallinn: Eesti Raamat.

Seton-Thompson, Ernest 1974. Lugusid loomadest. Tallinn: Eesti Raamat.

Thomas, Kathy 2003. Munchausen syndrome by proxy: Identification and diagnosis. Journal of Pediatric Nursing 18, lk 174-180. 